\title{
Cognitive-Behaviour Therapy for problem gambling: a critique of current treatments and proposed unified approach
}

\begin{abstract}
:
Background: There is evidence supporting the use of cognitive-behavioural therapy (CBT) in the treatment of problem gambling. Despite this, little is known about how CBT works and which particular approach is most effective. This paper aims to synthesize the evidence for current CBT and propose a more unified approach to treatment.

Methods: A literature review and narrative synthesis of the current research evidence of CBT for the treatment of problem gambling was conducted, focusing on the underlying mechanisms within the treatment approach.

Results: Several CBT approaches were critiqued. These can be divided into forms of exposure therapy (including aversion techniques, systematic desensitization, and other behavioural experiments) those focusing on cognitive restructuring techniques (such as reinforcement of non-gambling activity, use of diaries, motivational enhancement and audioplayback techniques and third wave techniques including mindfulness. Findings, in relation to treatment actions, from this synthesis are reported.

Conclusions: The debate surrounding the treatment of problem gambling has been conducted as an either/or rather than a both/and discourse. This paper proposes a new, unified approach to the treatment of problem gambling that incorporates the best elements of both exposure and cognitive restructuring techniques, alongside the use of techniques borrowed from mindfulness and other CBT approaches.
\end{abstract}

Keywords: problem gambling; cognitive-behavioural therapy; theory. 


\section{Background}

Problem gamblers experience a conditioning process to gambling cues, leading to future oriented pleasure in the form of optimism that 'their day will come'. The gambler is, therefore, oriented towards seeking reward resulting in impulsive behaviours whenever this is triggered (Balodis, Thomas, \& Moore, 2014). Once triggered, the gambler links the perceived reward with stimulus associations giving rise to the urge. At the same time gamblers have compromised executive functions whereby they persevere with gambling despite the contrary evidence of losing (Ledgerwood et al., 2012) and a loss of inhibition with poor judgment (Reid, McKittrick, Davtian, \& Fong, 2012). Gamblers have reward systems that differs from non-gamblers having behaviours leading to anti-reward (Volkow, Wang, Tomasi, \& Baler, 2013) and a decrease in positive reward (Miedl, Peters, \& Buchel, 2012). A number of therapeutic approaches have been considered to tackle these gamblers experiences.

The historical development of treatments for problem gambling

In the nineteenth century, the principal approaches to problem gamblers were often punitive with the gambler being imprisoned or fined. Alternatively, gambling was seen as amoral, rather than illegal, and banned altogether (Ferentzy \& Turner, 2013). These societally imposed sanctions did not attempt to provide help to individual sufferers (Schwartz, 2007). There were also attempts to regulate gambling because of its potential to cause harm and to be criminally manipulated e.g. through money laundering (McKibbin, 1979). These attempts continue today using a public health framework, with the aim of encouraging 'responsible' or 'healthy’ gambling behaviours (Korn \& Shaffer, 1999). Prevention interventions are aimed at the gambler, the gambling activities, expenditure, the gambling environment and the family, social, economic and political contexts in which the industry operates.

With the development of psychodynamic psychotherapy, attempts were made to treat problem gambling based on various psychoanalytical assumptions about the root cause with 
little effect (Rosenthal \& Rugle, 1994). Most psychodynamic formulations suggest the gambler is exhibiting mastibatory patterns associated with the fear of being caught. This was first proposed by Sigmund Freud (1928) in his case study of the author Dostoevsky and later expanded on by Bergler (1939). Gamblers Anonymous (GA) became a prominent movement that promoted total abstinence (Kelly, Magill, \& Stout, 2009). There is marginal evidence to support GA as an effective treatment approach, although that is not to say it does not work. The anonymous nature of GA prevents genuine research to a certain extent. The research that has taken place reports poor outcomes (Stewart \& Brown, 1988), possibly because of the focus within GA on total abstinence. Petry (2003) suggests GA, as an adjunct to individual therapy, is associated with higher success rates, a view supported by Lesieur and Blume (1991). On the other hand, Stinchfield and Winters (1996) found that attendance at GA did not significantly improve outcomes for clients.

Solution-Focused Brief Therapy (SFBT) has been used to treat problem gamblers (Berg \& Briggs, 2002; Strong, 2011) and is based on solution-building rather than problemsolving (Shazer et al., 1986). In SFBT, the focus is not placed on the problem of gambling behaviour but on the solution and how the person's world will be different and better once gambling no longer happens. SFBT is gaining increasing popularity in mainstream health and social care agencies, particularly for treating young people (May-Chahal \& Colemen, 2003; May-Chahal, Wilson, Humphreys, \& Anderson, 2012; Parton \& O'byrne, 2001). There have been some concerns that SFBT has yet to be properly evaluated (Corcoran \& Pillai, 2009), particularly in relation to gambling.

Similarly, hypnotherapy has also been used to treat problem gambling but there is limited evidence to support its use, with no efficacy trials having been conducted to date. Any discussion of the use of hypnosis therefore has to be theoretical. In a single case report, 
Griffiths (1996) reported total success using hypnotherapy for gambling problems. However, this has not been followed up with larger studies.

The earliest form of behaviour therapy was based on aversion techniques (AT) (Barker \& Miller, 1968; Cross, 1966; Koller, 1972; Seager, 1970). Although, reports indicated that gambling either stopped or that there was significant improvement, the evidence can only be described as circumstantial and based on single cases or small groups. In a randomised trial, it was shown that only one third of AT participants stopped gambling (McConaghy, Blaszczynski, \& Frankova, 1991). However, in an experimental design it was found that aversive learning was unlikely to be effective in reducing gambling urges (Brunborg et al., 2012).

Procedures based on Systematic Desensitisation (SD) have been described with limited outcomes. Imaginal Desensitisation (ID), a variant of SD suggested by McConaghy, Armstrong, Blaszczynski and Allcock (1983), paired relaxation with a behavioural approach using the imagination and was shown to be superior to other behavioural methods. ID was shown to be effective for $80 \%$ of participants which was later confirmed in a long term follow-up study (McConaghy et al., 1991). However, there were flaws in the research, most notably, the incorrect use of exposure, which was prescriptive rather than response dependent. Exposure requires the person to remain in their urge situation for as long as it takes to bring about a meaningful reduction (usually 50\% from maximum reached during task). In McConaghy et al's study, gamblers were given the choice of remaining in the situation for 20 minutes or one hour depending on which group they were in. This meant the gambler may not have experienced enough time for the urge to reduce by $50 \%$ or more from the highest level. Despite this, more than half responded positively to exposure treatments (McConaghy et al., 1991). In a six month follow up ID plus motivational interviewing was considered to be successful, although the authors note worsening in follow-up (Battersby, 
Oakes, Author, Forbes, \& Pols, 2008; Grant, Donahue, Odlaug, \& Kim, 2011; Author \& Battersby, 2000, 2001, 2013). It could be argued that the success rate of ID was due to the exposure element alone and that the relaxation component was unnecessary. Individuals treated with imaginal and live exposure show a positive response quicker than clients treated only with ID, and gains are maintained long term (Battersby, Oakes, Author, Forbes, \& Pols, 2008; Author \& Battersby, 2000, 2001, 2013).

A number of reviews have attempted to shed light on which specific treatments are effective (Leung \& Cottler, 2009; Stea \& Hodgins, 2011) with treatments based on cognitivebehavioural therapy and psychopharmacological therapies starting to show promise (Pallesen, Mitsem, Kvale, Johnsen, \& Molde, 2005). Cowlishaw and colleagues (2012) suggest that, while the evidence for CBT is strongest, the quality of the studies and the multiple limitations they present would indicate biased estimates for CBT interventions.

The most commonly used pharmaceutical approach is Selective Serotonin Reuptake Inhibitors (SSRIs), which appear to target the depresogenic aspects of gambling. The use of opioid antagonists with problem gamblers provides some parallels with psychological treatments. These pharmaceutical agents act on dopaminergic transmission reducing both gambling urges and thoughts and also altering gambling behavior (Hodgins, Stea \& Grant, 20111). Such modulation would indicate the mechanism for exposure to be acting in a similar way. However, as with anti-exposure, a concern would be the reversal of this response on cessation of the drug. Despite showing some initial promise the opioid antagonist, naltrexone, administered as needed, was recently found to provide no substantial additional benefit to pathological gamblers receiving psychological support (Kovanen et al. 2016). In addition, being able to identify the neural correlates of gambling would provide better support for targeted treatments. Potenza et al (2003) demonstrated, in a neuroimaging study, a link between responses to anticipatory urges for gambling cues leading to poor impulse control. 
This link would further support treatment that breaks this response to the anticipatory urge including exposure, cognitive restructuring and opioid antagonists. Both, exposure- through extinction of the urge response-and cognitive restructuring — through disconfirming the thinking leading to the response- - target the urge.

Hence, the dominant psychological approaches to treatment of gamblers have been derived from behavioural and cognitive-behavioural models (Smith, Dunn, Harvey, Battersby, \& Pols, 2013; Stuhlmiller \& Author, 2009). However, there is a lack of evidence from gambling meta-analyses to guide clinicians, because of the small number of high quality RCTs and too much heterogeneity between studies. In this study, a narrative synthesis methodology was used to examine cognitive and behavioral approaches to gambling treatment, in order to fill this evidence gap.

This review will examine the behavioral and/or cognitive treatments used to treat problem gambling in more detail. A narrative synthesis of the key elements of these approaches will be made and a rationale will be developed for incorporating different approaches into a unified model of treatment.

\section{Method}

A literature review was conducted using narrative synthesis, rather than a systematic review. The aim was to synthesize the main treatment elements in order to identify a unified model of treatment to be tested in future research. Peer-reviewed journal articles published were reviewed in the following databases from 1980 onwards (EBSCOhost including PsycINFO, Medline). The year 1980 was chosen in order to ensure that all works describing CBT or forms of treatment using elements of the approach were included. Unfortunately, this meant that key references from prior to 1980 were excluded. However, the results from these studies have been incorporated into the introduction above. The search terms used were (TI (Gambling OR Gambler ) AND (cognitive OR behavior OR behaviour) AND therapy)) were 
used using the databases above for inclusion into the review. Articles were included if they were studies into treatment efficacy or effectiveness, using a cognitive or behavioral approach to problem gambling. This generated a total of 10079 articles and all relevant studies have been analyzed below.

\section{Insert Prisma diagram}

The main studies examined related to either behavioral therapy in the form of Exposure Therapy (ET) with or without response prevention or cognitive-behavioral therapy in the form of Cognitive Restructuring (CR). In brief, exposure therapy aims to encourage the person experiencing a strong emotional response to enter and remain in that arousal situation and remain there until the response abates. In the case of gamblers this emotional response is often described as an urge. The main elements to exposure are: 1) developing a hierarchy of urge provoking situation; 2) tackling this hierarchy from the least provoking upwards; 3) conducting exposure session where the person remains in the situation until the urge reduces by at least 50\% (Subjective Units of Distress Scale) (Wolpe, 1969); and 4) repeating this same session at least three times per week or until it no longer evokes the urge and the gambler remains focused on the urge without any attempt to artificially reduce it, before moving to the next step of the hierarchy (Author \& Battersby, 2013). While exposure is aimed at habituation (Rosqvist, 2012) of the urge response, there is also a natural change in the way gamblers think about their gambling.

Cognitive restructuring with or without behavioral experiments involves a process of: 1) identifying erroneous thinking related to gambling situations; 2) considering the relative merit of that thinking; 3) identifying alternative ways of considering the same situation; 4) testing out this alternative way of thinking; and 5) evaluating the response. This may be done in session with the therapist directly challenging the erroneous thinking. Alternatively, the therapists and gambler may agree on a behavioral experiment or task, carried out after the 
session (Smith, Battersby, Harvey, Pols, \& Ladouceur, 2015). In both cases an initial period of stimulus control is used including restricting money and access to gambling. This is simply to bring about immediate control which, over time, is returned to the gambler.

\section{Results}

\section{Studies into Exposure Therapy}

Exposure therapy (ET) has been shown to be effective in a small number of studies (Echeburúa, Báez, \& Fernández-Montalvo, 1996; Hodgins, Currie, el-Guebaly, \& Peden, 2004; Author \& Battersby, 2013; Symes \& Nicki, 1997) and using a variety of approaches (Giroux et al., 2013; Oakes, Battersby, Pols, \& Cromarty, 2008; Author, Thomas, \& Battersby, 2006). The basic principle underlying exposure is extinction of the response (e.g. the urge to gamble) to a particular emotional reaction (e.g. excitement) to a stimulus or cue (e.g. seeing flashing lights of a poker machine). Breaking down the learned association between gambling cues and the subsequent emotional responses make exposure therapy one of the potentially effective treatment technique for problem gamblers (Dickerson \& O'Connor, 2006; Pallesen et al., 2005).

In two naturalistic studies, Author \& Battersby (2001, 2013), report high rates of success (70\%) for ET in a problem gambling clinic population. These studies were not controlled and the efficacy of ET was not tested against any other approaches and so can only be seen as an indicative outcome. Similar results were found in other reports (Kushner et al., 2007) including use of ET in a single session approach (Author et al., 2006). Currently, a study is underway which aims to tease out the efficacy of different methods including ET (Smith et al., 2010; Smith et al., 2015).

\section{Studies into Cognitive Restructuring}

A number of approaches employing principles of cognitive restructuring (CR) have been described (Petry, 2005; Sylvain, Ladouceur, \& Boisvert, 1997; Toneatto, 2002). The 
most consistent has been that of Ladouceur, Sylvain, Letarte, Giroux and Jacques (1998) who suggest common misunderstandings about crucial elements of games of chance which lead to an overestimation of the chance of winning, belief that skills influence outcome, and erroneous beliefs of independent events and randomness (Fortune \& Goodie, 2012; Gooding \& Tarrier, 2009; Ladouceur et al., 2003). This approach provides education regarding chance and randomness and challenges clients' erroneous beliefs, while simultaneously encouraging stimulus control and avoidance of gambling cues. This is based on principles of abstinence, rather than harm minimization, and can be seen as the opposite of ET or 'anti-exposure'. Ladouceur and colleagues concluded that this approach was effective in many cases. However, improvement rarely reached 50\% of treatment group participants (Ladouceur \& Lachance, 2007a; Ladouceur et al., 1998; Sylvain et al., 1997). The use of anti-exposure which does not encourage gamblers to face their urges in the presence of gambling specific cues may result later in relapse and could explain the poor response described in the study above.

Petry (2005) proposes an approach involving the reinforcement of non-gambling activities. Clients are encouraged to use an activity diary to monitor their gambling and nongambling days. When the client has not gambled they are encouraged to select from a range of reward options, which increase with longer periods of abstinence. If a pattern of gambling is established, avoidance is encouraged and increasing pleasurable non-gambling activities are introduced. Relaxation is encouraged as an urge reducer. Finally, a form of cognitive restructuring takes place. This approach has similarities with modern behavioral activation (Dimidjian, Barrera, Martell, Muñoz, \& Lewinsohn, 2011; Mazzucchelli, Kane, \& Rees, 2010). As with Ladouceur's model, 'anti-exposure' is encouraged in the form of urge avoidance. A comparison was made between GA, GA+CBT workbook and GA+CBT. The authors concluded that all three groups showed an equal rate of success at $60 \%+$ and that 
individual CBT was shown as most effective, despite CBT not being tested alone (Petry et al., 2006). It could easily be argued that Gamblers Anonymous (GA) was having the main effect and CBT was adding nothing extra. At no point during the trial were any of the participants abstinent from gambling. While there is a reasonable argument for controlled gambling (Dickerson \& Weeks, 1979), the lack of abstinence raises concerns.

Further variants of CBT have been described, including that of Wulfert, Blanchard, Freidenberg and Martell (2006) who incorporate motivational enhancement (MBCT) techniques to standard CBT as prescribed by Ladouceur and Lahance (2007b). The main difference between this and standard CBT was three active treatment sessions in which the client's motivation to engage in therapy were established. This is based on the motivational interviewing (MI) approach of Rollnick and Miller (1995). In a small pilot of their approach, the results for nine male horse racing gamblers were described with eight having significant reductions in gambling severity. The follow-up for this study was brief (6 months) and revealed seven of the nine to be either abstinent or to have achieved an acceptable level of controlled gambling.

Again although these results are promising, several problems need to be acknowledged. First, only a very small number of clients were treated. It is highly likely that with only nine people and what appear to be three therapists, it would have been possible for therapists to actively support them in an ongoing manner. Second, it is unclear if the results were sustained in the long term. Finally, the assumption that the addition of the MI was important to treatment success was not well founded. As there were no comparison groups consisting of individuals who did not receive MI but did get the other elements, this assumption cannot be made. Wulfert, Blanchard, Freidenberg and Martell (2006) have since carried out a quasi-controlled study where they compared 11 clients who received MBCT and a further 12 clients were being treated at the same service but without the motivational 
elements. The results revealed a much higher completion rate in the experimental group with $60 \%$ achieving abstinence and a further $20 \%$ being considered much improved.

Mindfulness is showing some early promise in treating gamblers. In one study of group mindfulness, it was reported that all subjects had improved over time. However, this was not a significant improvement (Chen, Jindani, Perry, \& Turner, 2014). It has been suggested that this improvement may have been due to experiential avoidance, which was considered a major maintenance factor for problems of urge or anxiety. Therefore, it would appear that while improvement occurs in mindfulness, this may simply be encouraging the person to avoid the emotion rather than dealing with it in the long term (Riley, 2014).

\section{Studies into Combined Approaches}

Griffiths (1993) describes the use of audio-playback where the individual gambler is asked to speak their thoughts out loud during play, and these are recorded. Listening to the recordings gives the gambler the opportunity to consider their process of thinking while gambling. One participant stopped gambling as a result of listening to the recording, as he came to understand the futility of his beliefs. This approach is based on the 'thinking aloud' approach (Ericsson \& Simon, 1985; Fox, Ericsson, \& Best, 2011) and could be considered both a form of exposure (i.e. exposing gamblers to their thoughts) or a form of cognitive restructuring (i.e. the gambler recognizes the erroneous nature of their thoughts). This technique may well be a useful means by which both exposure and cognitive restructuring could be achieved. Behavioral experiments are widely used and are considered at least as effective as exposure alone (McMillan \& Lee, 2010).

In one quasi-experimental study, ET was shown to be superior to a wait list control, individual cognitive restructuring and a combined cognitive restructuring and exposure (Echeburúa et al., 1996). This study had a number of limitations, in particular the small sample and an unclear cognitive component. Despite these limitations exposure was correctly 
administered and shown to be effective in $69 \%$ of cases at one-year follow-up, compared with only $38 \%$ of the cognitive restructuring group. The authors concluded that combining exposure therapy with cognitive restructuring produced no additional benefits.

\section{Relapse prevention}

In addition to the two prominent approaches described above, there is clear evidence for relapse prevention strategies being included to ensure treatment gains are maintained in follow-up (Author \& Battersby, 2014). Generally, methods based on the work of Marlatt and Gordon are used (1985). Their approach suggests the therapist, in collaboration with the person with a [gambling] problem, identify high and low risk situations that may lead to future gambling and events which may generate negative emotional responses (Rash \& Petry, 2014; Smith, Battersby, Pols, Harvey, Oakes, \& Baigent, 2015). Once future relapse scenarios have been identified, strategies for managing these are agreed. In both ET and CR continued practice is also encouraged, where the person may carry out exposure task/behavioural experiments with decreasing frequency and report back to therapists in follow-up sessions (Riley, 2015; Author \& Battersby, 2014). There is also strong evidence from other fields that encouraging alternative rewards post treatment provides a strong basis for reducing relapse e.g., obesity (Epstein, Lin, Carr, \& Fletcher, 2012) and smoking (Goelz, et al., 2014).

\section{Mechanism of change}

There have been several major reviews which have examined the effects of CBT (ET and/or CR) on gamblers concluding there is sufficient evidence to support both approaches either alone or in combination (Gooding \& Tarrier, 2009; Pallesen et al., 2005; Raylu, Loo, \&

Oei, 2013; Toneatto \& Ladoceur, 2003). However, reviewers give advisory notes regarding the quality of trials to date in particular noting small sample sizes and the lack of follow-up data. A growing concern is the need to develop an understanding of the mechanisms of 
change during therapy. Evidence to support a clear hypothesized mechanism of action is limited. For example, no mediation analyses have been conducted using RCT data to test the translational effects of urge reduction and extinction (mediator) on exposure techniques (e.g. imaginal desensitization) to outcome (e.g. absence of gambling behaviour).

Ladouceur and colleagues (1998) propose the means of producing change is direct, through the exploration of erroneous beliefs during the cognitive restructuring processes. On the other hand, research using exposure therapy suggests there is a change in behaviour which, in turn, leads to a reduction in gambling. Although both approaches have some face validity, there are other possible explanations. Exposure does not simply target behaviour in order for extinction to occur. The modern practice of exposure clearly targets thoughts, physiology and behaviours to enact emotional change.

Equally, challenging erroneous beliefs not only targets thoughts, but also leads to reduction of behaviour and to changes in physiology. It is vital these issues are addressed and a unified model of CBT is developed for the treatment of gambling. Comparison of the different models is essential since there is evidence for both exposure therapy and cognitive restructuring, perhaps with anti-exposure elements. Exposure appears to produce higher rates of success demanding its inclusion as a preferred treatment for gambling problems, if not as a single mode of treatment but as part of a broader CBT approach. Clark (2010) argues for an overarching theory of gambling synthesizing the interactions of cognitive distortions and psychobiological responses which lends support to the above. In this synthesis model, Clark proposes there is reinforcement learning taking place during the expression of cognitive distortions (p. 324) centered on the primary reward of money in gamblers. Therefore, the extinction of this reinforcement through exposure would act to modify these cognitive distortions.

\section{Discussion}


A number of issues are raised when reviewing the efficacy of treatments for PG. On balance non-pharmacological treatments based on CBT are showing the greater promise. However, the major limitations addressed here need to be dealt with. There have been numerous gambling trials lacking transparency particularly in the reporting of randomization (e.g., sequence generating). Many trials make large claims based on low samples and variable inclusion/exclusion criteria. It is therefore difficult to judge the quality of such trials. In particular, the presence of comorbidities is often used as an exclusion criterion, making the results somewhat questionable in relation to clinical populations.

The mechanism of change must also be considered when choosing certain approaches. Many CBT treatments encourage stimulus control methods leading to anti-exposure advice, despite treatments based on exposure having merit. Is it justifiable to refuse a potentially helpful approach simply because it is does not fit the therapist's model? There needs to be a clearly defined and replicable, efficacious treatment approach that could be offered to gamblers.

Exposure Therapy operates on a process of habituation or extinction with the basic assumption being that associative learning underlies both the development and treatment of excessive urges to gamble (McLean \& Foa, 2011). McLean \& Foa (2011) suggest an emotional processing theory of fear that is closely aligned to that of the gambling urge. In their model they suggest the fear (urge) exists in memory as a cognitive structure and as such should be amenable to cognitive change. This structure includes information about the urge stimuli (slot machine sounds and images, roulette wheel spinning), the urge responses (excitement, increasing bet sizes) and meaning ('the big win is around the corner', 'It's my lucky day’). The argument would follow that exposure provides a means to such change by: 1) activating the urge structure in the absence of urge outcomes and correcting exaggerated probability estimates of winning; 2) strengthen the distinction between remembering previous 
gambling and the experience of that gambling, altering the associations between the gambling memory and meaning; and 3) exposure to the urge allows the gambler to re-evaluate erroneous urge-related cognitions about themselves, the world and the future (e.g., 'I can beat the machine', 'this is a lucky machine' and 'the big win is just around the corner') that are at the core of the urge structure. On the other hand, cognitive restructuring, with or without exposure, enables the gambler to understand the erroneous nature of their thinking which would help break the patterns of perseveration and the poor judgements that gambling will ultimately be successful.

Finally, post-treatment relapse prevention approaches would ensure therapeutic gains were maintained so that the gambler does not return to previous behavioural and cognitive patterns that increase their likelihood to return to previous behaviour. The elements of a unified model would consist of:

- Initial stimulus control e.g., having others control the gambler’s money;

- Exposure to gambling cues;

- Cognitive restructuring to develop and maintain urge reduction gains; and

- A relapse plan that encourages continual use of the techniques used in therapy.

These views are based on the current best evidence which supports CBT. As other approaches achieve acceptable efficacy they too could be considered for better targeting of treatment. Research may be better spent understanding the different qualities of gamblers and then matching treatments to the individual rather than taking a one size fits all approach, or an, everything will eventually have some kind of effect approach.

Conclusion

Evidence suggests both cognitive and behavioral approaches to problem gambling are helpful. Some cognitive approaches have behavioral effects and include forms of behavioural therapy (such as relaxation therapy). Some behavioural approaches such as systematic 
desensitization has cognitive effects and include forms of cognitive therapy (such as motivational interviewing). To date, the discussion about what treatment works best has focused on an either/or approach, rather than a both/and way of thinking. Given the complexity of gambling, perhaps it is time to consider a unified approach that incorporates the best of both worlds.

A unified CBT approach would incorporate elements of both exposure therapy and cognitive restructuring, and would consist of a period of abstinence or urge avoidance with stimulus control, followed by controlled exposure to gambling cues, the development and maintenance of urge reduction, and a practical relapse prevention plan that incorporated ideas from therapy. It is clear there is a need for an initial period of stopping gambling. Therefore, the use of control techniques in the first instance would appear to make sense. This may include a clearly negotiated stop day, or temporary money management by family members or friends. Once the gambler has experienced this period of abstinence, then they would be better prepared to tackle their active urge cues, with a greater success of not responding with gambling. The link achieved through exposure, between feeling an urge to gamble and being able to control this, is very powerful and provides the gambler with a strong cognitive shift. A period of such urge management can then be supported with the inclusion of specific cognitive appraisal in gambling situations through behavioural experiments. Once this unified approach has been successful, the need to maintain any gains during therapy must be addressed. The importance of relapse prevention cannot be underestimated. In this proposed model, a combination of continuing therapy homework with early identification of relapse triggers is required. The gambler would also need to consider alternative rewarding behaviors that replace gambling as the primary motivator. The identification of such alternatives can prove difficult, and must be person specific. Developing a list of high and low risk situations coupled with recognition of negative emotional states in relapse prevention would provide the 
structure for ensuring the alternative rewards were effective. The danger would be replacing gambling with another habit forming behavior. Therefore, the relapse plan should establish a range of alternatives rather than relying on one. Finally, it cannot be stressed enough that regular follow-up of gamblers post active treatment is essential. Ensuring the gambler is continuing with their homework and adhering to their relapse plan will enable earlier detection of potential relapse and therefore ensure additional booster sessions are given.

\section{References}

Balodis, S., Thomas, A., \& Moore, S. (2014). Sensitivity to reward and punishment: Horse race and EGM gamblers compared. Personality and Individual Differences, 56, 29-33. Barker, J., \& Miller, M. (1968). Aversion therapy for compulsive gambling. The Journal of nervous and mental disease, 146(4), 285-302.

Battersby, M., Oakes, J., Author, B., Forbes, A., \& Pols, R. (2008). Cognitive behavioral therapy for problem gamblers. In the pursuit of winning, 179-197.

Berg, I. K., \& Briggs, J. R. (2002). Treating the person with a gambling problem. Journal of Gambling Issues.

Bergler, E. (1939). On the psychology of the gambler. The Psychoanalytic Review (19131957), 26, 565.

Brunborg, G. S., Johnsen, B. H., Mentzoni, R. A., Myrseth, H., Molde, H., Lorvik, I. M., .. . Pallesen, S. (2012). Diminished aversive classical conditioning in pathological gamblers. Addiction, 107(9), 1660-1666.

Chen, P., Jindani, F., Perry, J., \& Turner, N. L. (2014). Mindfulness and problem gambling treatment. Asian Journal of Gambling Issues and Public Health, 4(1), 1-17.

Clark, L. (2010). Decision-making during gambling: an integration of cognitive and psychobiological approaches. Philosophical Transactions of the Royal Society of London B: Biological Sciences, 365(1538), 319-330. 
Corcoran, J., \& Pillai, V. (2009). A review of the research on solution-focused therapy. British Journal of Social Work, 39(2), 234-242.

Cowlishaw, S., Merkouris, S., Dowling, N.A., Anderson, C., Jackson, A.C. \& Thomas, S.A. (2012). Psychological interventions for the treatment of pathological and problem gambling. Cochrane Database of Systematic Reviews 2011, Issue 1 Art. No: CD008937.DOI: 10.1002/14651858.CD008937.

Cross, I. (1966). Aversion therapy treatment for compulsive gambling. Nursing mirror and midwives journal, 123(7), 159.

Dickerson, M. G., \& O'Connor, J. (2006). Gambling as an addictive behaviour: Impaired control, harm minimisation, treatment and prevention: Cambridge University Press.

Dickerson, M. G., \& Weeks, D. (1979). Controlled gambling as a therapeutic technique for compulsive gamblers. Journal of Behavior Therapy and Experimental Psychiatry, 10(2), 139-141.

Dickson-Gillespie, L., Rugle, L., Rosenthal, R. \& Fong, T. (2008). 'Preventing the incidence and harm of gambling problems', Journal of Primary Prevention, 29, 37-55.

Dimidjian, S., Barrera, M., Martell, C., Muñoz, R. F., \& Lewinsohn, P. M. (2011). The origins and current status of behavioral activation treatments for depression. Annual Review of Clinical Psychology, 7, 1-38.

Echeburúa, E., Báez, C., \& Fernández-Montalvo, J. (1996). Comparative effectiveness of three therapeutic modalities in the psychological treatment of pathological gambling: Long-term outcome. Behavioural and Cognitive Psychotherapy, 24, 51-72.

Epstein, L. H., Lin, H., Carr, K. A., \& Fletcher, K. D. (2012). Food reinforcement and obesity. Psychological moderators. Appetite, 58(1), 157-162.

Ericsson, K. A., \& Simon, H. A. (1985). Protocol analysis: MIT press. 
Ferentzy, P., \& Turner, N. E. (2013). The History of Gambling and Its Intersection with Technology, Religion, Medical Science, and Metaphors. New York: Springer.

Fortune, E. E., \& Goodie, A. S. (2012). Cognitive distortions as a component and treatment focus of pathological gambling: a review. Psychology of addictive behaviors, 26(2), 298.

Fox, M. C., Ericsson, K. A., \& Best, R. (2011). Do procedures for verbal reporting of thinking have to be reactive? A meta-analysis and recommendations for best reporting methods. Psychological bulletin, 137(2), 316.

Freud, S. (1945). Dostoevsky and parricide (1928). The International journal of psychoanalysis, 26, 1.

Giroux, I., Faucher-Gravel, A., St-Hilaire, A., Boudreault, C., Jacques, C., \& Bouchard, S. (2013). Gambling Exposure in Virtual Reality and Modification of Urge to Gamble. Cyberpsychology, Behavior, and Social Networking, 16(3), 224-231.

Goelz, P. M., Audrain-McGovern, J. E., Hitsman, B., Leone, F. T., Veluz-Wilkins, A., Jepson, C., ... \& Schnoll, R. A. (2014). The association between changes in alternative reinforcers and short-term smoking cessation. Drug and alcohol dependence, 138, 6774.

Gooding, P., \& Tarrier, N. (2009). A systematic review and meta-analysis of cognitivebehavioural interventions to reduce problem gambling: Hedging our bets? Behaviour Research and Therapy, 47(7), 592-607.

Grant, J. E., Donahue, C. B., Odlaug, B. L., \& Kim, S. W. (2011). A 6-month follow-up of imaginal desensitization plus motivational interviewing in the treatment of pathological gambling. Annals of clinical psychiatry: official journal of the American Academy of Clinical Psychiatrists, 23(1), 3. 
Griffiths, M. (1993). Tolerance in gambling: An objective measure using the psychophysiological analysis of male fruit machine gamblers. Addictive Behaviors, 18(3), 365-372.

Griffiths, M. (1996). Behavioural addiction: an issue for everybody? Employee Counselling Today, 8(3), 19-25.

Hodgins, D., Currie, S., el-Guebaly, N., \& Peden, N. (2004). Brief motivational treatment for problem gambling: a 24-month follow-up. Psychology of addictive behaviors, 18(3), 293.

Hodgins, D., Stea, J., \& Grant, J. (2011). Gambling disorders. The Lancet, 378(9806), 18741884, doi:10.1016/s0140-6736(10)62185-x.

Kelly, J. F., Magill, M., \& Stout, R. L. (2009). How do people recover from alcohol dependence? A systematic review of the research on mechanisms of behavior change in Alcoholics Anonymous. Addiction Research \& Theory, 17(3), 236-259.

Koller, K. (1972). Treatment of poker-machine addicts by aversion therapy. The Medical Journal of Australia, 1(15), 742.

Kovanen, L., Basnet, S., Castrén, S., Pankakoski, M., Saarikoski, S. T., Partonen, T., ... \& Lahti, T. (2016). A Randomised, Double-Blind, Placebo-Controlled Trial of AsNeeded Naltrexone in the Treatment of Pathological Gambling. European addiction research, 22(2), 70-79.

Kushner, M. G., Abrams, K., Donahue, C., Thuras, P., Frost, R., \& Kim, S. W. (2007). Urge to gamble in problem gamblers exposed to a casino environment. Journal of Gambling Studies, 23(2), 121-132.

Ladouceur, R., \& Lachance, S. (2007a). Overcoming pathological gambling: therapist guide: Oxford University Press New York. 
Ladouceur, R., \& Lachance, S. (2007b). Overcoming your pathological gambling: Workbook (Vol. 2): Oxford University Press.

Ladouceur, R., Sylvain, C., Boutin, C., Lachance, S., Doucet, C., \& Leblond, J. (2003). Group therapy for pathological gamblers: A cognitive approach. Behaviour Research and Therapy, 41(5), 587-596.

Ladouceur, R., Sylvain, C., Letarte, H., Giroux, I., \& Jacques, C. (1998). Cognitive treatment of pathological gamblers. Behaviour Research and Therapy, 36(12), 1111-1119.

Ladouceur, R., \& Walker, M. (1996). A cognitive perspective on gambling. In: Salkovskis, P.M. (ed.), Trends in cognitive-behavioural therapies (pp. 89-120). New York: John Wiley \& Sons.

Ledgerwood, D. M., Orr, E. S., Kaploun, K. A., Milosevic, A., Frisch, G. R., Rupcich, N., \& Lundahl, L. H. (2012). Executive function in pathological gamblers and healthy controls. Journal of Gambling Studies, 28(1), 89-103.

Lesieur, H. R., \& Blume, S. B. (1991). Evaluation of patients treated for pathological gambling in a combined alcohol, substance abuse and pathological gambling treatment unit using the Addiction Severity Index. British journal of addiction, 86(8), 1017-1028.

Leung, K. S., \& Cottler, L. B. (2009). Treatment of pathological gambling. Current Opinion in Psychiatry, 22(1), 69-74.

López Viets, V.C., \& Miller, W.R. (1997). Treatment approaches for pathological gamblers. Clinical Psychology Review, 17, 689-702.

Marlatt, G. A., \& Gordon, J. R. (1985). Relapse prevention: A self-control strategy for the maintenance of behavior change. New York: Guilford.

May-Chahal, C., \& Colemen, S. (2003). Safeguarding children and young people: Psychology Press. 
May-Chahal, C., Wilson, A., Humphreys, L., \& Anderson, J. (2012). Promoting an EvidenceInformed Approach to Addressing Problem Gambling in UK Prison Populations. The Howard Journal of Criminal Justice.

Mazzucchelli, T. G., Kane, R. T., \& Rees, C. S. (2010). Behavioral activation interventions for well-being: A meta-analysis. The journal of positive psychology, 5(2), 105-121.

McConaghy, N., Armstrong, M. S., Blaszczynski, A., \& Allcock, C. (1983). Controlled comparison of aversive therapy and imaginal desensitization in compulsive gambling. British Journal of Psychiatry, 142, 366-372.

McConaghy, N., Armstrong, M. S., Blaszczynski, A., \& Allcock, C. (1988). Behavior completion versus stimulus control in compulsive gambling: Implications for behavioral assessment. Behavior Modification, 12, 371-384.

McConaghy, N., Blaszczynski, A., \& Frankova, A. (1991). Comparison of imaginal desensitisation with other behavioural treatments of pathological gambling: A two- to nine-year follow-up. British Journal of Psychiatry, 159, 390-393.

McKibbin, R. (1979). Working-class gambling in Britain 1880-1939. Past \& Present(82), 147-178.

McLean, C. P., \& Foa, E. B. (2011). Prolonged exposure therapy for post-traumatic stress disorder: A review of evidence and dissemination. Expert review of neurotherapeutics, 11(8), 1151-1163.

McMillan, D., \& Lee, R. (2010). A systematic review of behavioral experiments vs. exposure alone in the treatment of anxiety disorders: A case of exposure while wearing the emperor's new clothes? Clinical Psychology Review, 30(5), 467-478.

Miedl, S. F., Peters, J., \& Buchel, C. (2012). Altered neural reward representations in pathological gamblers revealed by delay and probability discounting. Archives of general psychiatry, 69(2), 177. 
Oakes, J., Battersby, M., Pols, R., \& Cromarty, P. (2008). Exposure therapy for problem gambling via videoconferencing: A case report. Journal of Gambling Studies, 24(1), 107-118.

Pallesen, S., Mitsem, M., Kvale, G., Johnsen, B. H., \& Molde, H. (2005). Outcome of psychological treatments of pathological gambling: a review and meta-analysis. Addiction, 100(10), 1412-1422.

Parton, N., \& O'byrne, P. (2001). Constructive social work: Macmillan Press.

Petry, N. (2003). Patterns and correlates of Gamblers Anonymous attendance in pathological gamblers seeking professional treatment. Addictive Behaviors, 28(6), 1049-1062.

Petry, N. (2005). Pathological gambling: Etiology, comorbidity, and treatment: American Psychological Association.

Petry, N., Ammerman, Y., Bohl, J., Doersch, A., Gay, H., Kadden, R., . . S Steinberg, K. (2006). Cognitive-behavioral therapy for pathological gamblers. Journal of consulting and clinical psychology, 74(3), 555.

Potenza, M. N., Steinberg, M. A., Skudlarski, P., Fulbright, R. K., Lacadie, C. M., Wilber, M. K., ... \& Wexler, B. E. (2003). Gambling urges in pathological gambling: a functional magnetic resonance imaging study.Archives of general psychiatry, 60(8), 828-836.

Raylu, N., Loo, J., \& Oei, T. P. (2013). Treatment of Gambling Problems in Asia: Comprehensive Review and Implications for Asian Problem Gamblers. Journal of Cognitive Psychotherapy, 27(3), 297-322.

Reid, R. C., McKittrick, H. L., Davtian, M., \& Fong, T. W. (2012). Self-Reported Differences on Measures of Executive Function in a Patient Sample of Pathological Gamblers. International Journal of Neuroscience, 122(9), 500-505.

Riley, B. J. (2015). The role of homework in exposure-based CBT outcome for problem gambling. International Gambling Studies, 15(3), 394-407. 
Riley, B. (2014). Experiential avoidance mediates the association between thought suppression and mindfulness with problem gambling. Journal of Gambling Studies, 30(1), 163-171.

Rollnick, S., \& Miller, W. R. (1995). What is motivational interviewing? Behavioural and Cognitive Psychotherapy, 23, 325-334.

Rosenthal, R. J., \& Rugle, L. J. (1994). A psychodynamic approach to the treatment of pathological gambling: Part I. Achieving abstinence. Journal of Gambling Studies, 10(1), 21-42.

Rosqvist, J. (2012). Exposure treatments for anxiety disorders: A practitioner's guide to concepts, methods, and evidence-based practice. Routledge.

Schwartz, D. G. (2007). Roll the bones: The history of gambling: Gotham Books.

Seager, C. (1970). Treatment of compulsive gamblers by electrical aversion. The British Journal of Psychiatry.

Shazer, S., Berg, I. K., Lipchik, E., Nunnally, E., Molnar, A., Gingerich, W., \& WeinerDavis, M. (1986). Brief therapy: Focused solution development. Family process, 25(2), 207-221.

Smith, D., Battersby, M., Harvey, P. W., Pols, R., \& Ladouceur, R. (2015). Cognitive versus exposure therapy for problem gambling: Randomised controlled trial. Behaviour research and therapy, 69, 100-110.

Smith, D. P., Battersby, M. W., Pols, R. G., Harvey, P. W., Oakes, J. E., \& Baigent, M. F. (2015). Predictors of relapse in problem gambling: A prospective cohort study. Journal of Gambling Studies, 31(1), 299-313.

Smith, D., Dunn, K., Harvey, P., Battersby, M., \& Pols, R. (2013). Assessing randomised clinical trials of cognitive and exposure therapies for gambling disorders: A systematic review. Behaviour Change, 30(3), 139. 
Smith, D., Harvey, P., Battersby, M., Pols, R., Oakes, J., \& Baigent, M. (2010). Treatment outcomes and predictors of drop out for problem gamblers in South Australia: A cohort study. Australian and New Zealand Journal of Psychiatry, 44(10), 911-920.

Stea, J., \& Hodgins, D. (2011). A critical review of treatment approaches for gambling disorders. Current drug abuse reviews, 4(2), 67-80.

Stewart, R. M., \& Brown, R. I. (1988). An outcome study of Gamblers Anonymous. The British Journal of Psychiatry, 152(2), 284-288.

Stinchfield, R., \& Winters, K. C. (1996). Treatment Effectiveness of Six State-supported Compulsive Gambling Treatment Programs in Minnesota: Randy Stinchfield and Ken C. Winters; Presented to Compulsive Gambling Treatment Program, Minnesota Department of Human Services: Minnesota Department of Human Services.

Strong, T. (2011). Approaching problem gambling with a discursive sensibility. Journal of Gambling Issues, 68-87.

Stuhlmiller, C., \& Author, B. (2009). Computer-assisted CBT for depression \& anxiety: increasing accessibility to evidence-based mental health treatment. Journal of psychosocial nursing and mental health services, 47(7), 32-39.

Sylvain, C., Ladouceur, R., \& Boisvert, J.-M. (1997). Cognitive and behavioral treatment of pathological gambling: A controlled study. Journal of consulting and clinical psychology, 65(5), 727.

Symes, B. A., \& Nicki, R. M. (1997). A preliminary consideration of cue-exposure, responseprevention treatment for pathological gambling behaviour: Two case studies. Journal of Gambling Studies, 13(2), 145-157.

Author, B., \& Battersby, M. (2000). The Effect of Treatment of Pathological Gamblers referred to a Behavioural Psychotherapy Unit: Outcome of three kinds of behavioural intervention. Towards. 
Author, B., \& Battersby, M. (2001). Nurse behavioural psychotherapy and pathological gambling: An Australian perspective. Journal of Psychiatric and Mental Health Nursing, 7(4), 335-342. doi: 10.1046/j.1365-2850.2000.00273.x

Author, B., \& Battersby, M. (2013). Cognitive Behaviour Therapy for Problem Gamblers: A Clinical Outcomes Evaluation. Behaviour Change, 30(01), 12-23. doi: http://dx.doi.org/10.1017/bec.2013.2

Author, B., \& Battersby, M. (2014). Treatment Completion in a Cognitive Behaviour Therapy Service for Problem Gamblers: Clinical Outcome Study. Journal of Addiction Research \& Therapy, 2013.

Author, B., Thomas, L., \& Battersby, M. (2006). Single-session exposure therapy for problem gambling: A single-case experimental design. Behaviour Change, 23(02), 148-155.

Toneatto, T. (2002). Cognitive therapy for problem gambling. Cognitive and Behavioral Practice, 9(3), 191-199.

Toneatto, T., \& Ladoceur, R. (2003). Treatment of pathological gambling: a critical review of the literature. Psychology of addictive behaviors, 17(4), 284.

Volkow, N. D., Wang, G.-J., Tomasi, D., \& Baler, R. D. (2013). Unbalanced neuronal circuits in addiction. Current opinion in neurobiology.

Williams, R.J., West, B.L., \& Simpson, R.I. (2012). Prevention of problem gambling: A comprehensive review of the evidence, and identified best practices. Report prepared for the Ontario Problem Gambling Research Centre and the Ontario Ministry of Health and Long Term Care. October 1, 2012.http://hdl.handle.net/10133/3121

Wolpe, Joseph (1969). The Practice of Behavior Therapy, New York: Pergamon Press. 
CBT for problem gambling: a unified approach

Wulfert, E., Blanchard, E. B., Freidenberg, B. M., \& Martell, R. S. (2006). Retaining Pathological Gamblers in Cognitive Behavior Therapy Through Motivational Enhancement A Pilot Study. Behavior Modification, 30(3), 315-340. 